\title{
Hotel management agreements: Balancing the interests of owners and operators
}

Received (in revised form): 26 November 2003

\section{Robert Schlup}

is a partner in the law firm of Bloch \& Partner with offices in Zurich and Munich, specialising in advising hotel owners and hotel operators about any form of hotelrelated transactions on a global basis. He is extensively engaged in all legal aspects of hotel development, financing and management and has represented several leading international hotel chains and many hotel owners in numerous countries. Robert has published a doctoral thesis on hotel management agreements and serves as a visiting professor in the Master in Hospitality Administration programme at the Ecole Hôtelière de Lausanne, where he teaches a course on hotel management agreements. He recently chaired a panel on the topic of balancing owners' and operators' interests in hotel management agreements at the International Hotel Conference in Monaco.

\section{Abstract}

This paper discusses the inherent conflict of interest between owners and operators under hotel management agreements and describes the most important business and legal issues that have to be observed from an owner's and an operator's perspective, respectively, when negotiating a hotel management agreement. At the same time, the paper gives an overview of the most significant contractual issues that should be covered in all hotel management agreements. The author concludes that only a balanced contract will allow both parties to achieve their business goals over time, and that the best approach to a balanced contractual basis is a mutual understanding by the parties of each other's main concerns.

\section{Keywords:}

approval rights, balance of economic risk, brand protection, cost control, group charges, guest data, hotel management agreements, management fees, operator, owner, termination clause

\section{INTRODUCTION}

Today it is an established principle of the international hospitality industry that ownership and operation of a hotel are more often than not separated. Only a small fraction of hotels that bear the name of recognised national or international brands are owned by the respective operators. In addition to properties that are owner operated, the following three concepts of operation have evolved over time: leases (either fixed or contingent), franchising and management agreements. Of these forms, management agreements are probably the most widespread in the quality hotel sector. A 


\section{Inherent conflict of interest}

\section{Advantage of balanced contract}

hotel management agreement can be defined as a written agreement between the owner of a hotel and an operator, by which the operator is appointed to operate and manage the hotel in the name, on behalf of and for the account of the owner and the operator is to receive a management fee in return. ${ }^{1}$

Compared to all other forms of operation where the party operating the hotel is also bearing the risk of such operation, the management agreement is clearly distinct: under a management agreement the full economic risk remains with the owner, while the operator is responsible for the operation of the hotel. In addition to this imbalance of risk, the management agreement is characterised by an inherent conflict of interest between the owner and the operator. The goal of the owner is the long-term economic success of the hotel and the appreciation of the hotel real estate. The owner has a direct interest that the hotel operates at a profit as he alone bears the risk of a loss. From a financial point of view, the highest priority of the owner is to generate sufficient operating cash flow to serve the debt on the property and optimise its return on investment. On the other hand, the primary focus of the operator is to generate the highest fee income possible and to promote the reputation and the interests of the hotel chain in order to increase the value of the brand. ${ }^{2}$ Based on the foregoing, it is quite obvious that, despite its popularity, the management agreement is the most problematic of all operating concepts in the hospitality industry.

The management agreement creates a long-term relationship between the parties which is heavily exposed to economic cycles. Due to its particular nature, neither party will benefit from a one-sided contract over time. Agreements that favour one party excessively will inevitably lead to conflicts that often escalate into costly legal disputes or result in early termination well before the contractual term.

Consequently, in the long run only a balanced management agreement can be in the best interest of both the owner and the operator.

Unfortunately, there is no standard form for a well-balanced hotel management agreement that would properly address the concerns of both parties in every case. There are too many factors that have to be taken into account in each individual project: type and size of a hotel, location, total investment cost, structure of financing, market segment and size of chain, services offered by the operator, etc. In addition, every single clause of a contract must be examined within the entire context of the agreement: while a party may be at a disadvantage with respect to a certain provision of concern, such a disparity may be compensated for by a concession of the other party regarding another key issue.

The best approach to a balanced agreement is for each party to try to understand the main concerns of the other. Only if owners and operators are aware of the issues on which the other side cannot compromise is it possible to arrive at a mutually beneficial contract. Furthermore, the parties should ensure that all issues of particular concern are already addressed in the course of their 
contract negotiations and covered in the final agreement. This paper is structured accordingly: first the most important issues from an owner's perspective are identified, then the major provisions of concern to operators are dealt with. The result gives an overview of the most significant contractual issues that should be covered in any hotel management agreement. One should note that the following conclusions are not based on an empirical survey, but rather on personal observations by the author, who has represented both owners and operators in many management agreement negotiations.

\section{KEY ISSUES FOR OWNERS}

\section{Control of costs}

\section{Alignment of interests}

Transparency

\section{Management fees}

According to a recent study, ${ }^{3}$ in Europe the average base fee (the part of the management fees that is calculated as a percentage of turnover) is 1.8 per cent of gross revenue and the average incentive fee (the part of the management fees that is calculated as a percentage of profit) is 6.9 per cent of gross operating profit (GOP). Obviously, owners have an interest to minimise the fees payable to the operator in consideration of its services. But rather than reducing the overall amount of fees, owners should primarily insist that most of the fee is performance based and only a small part is calculated on the basis of revenue. Under a fee structure emphasising the incentive component, more risk is shifted towards the operator and the interests of owner and operator are much better aligned. This is absolutely essential to overcome - at least partially — the immanent imbalance of risk.

\section{Group charges}

Group charges - also called system reimbursable expenses or central services fees - are fees or costs charged by the operator to the owner for system-wide services provided by the hotel chain. Such charges include expenditures for chain-wide sales and marketing efforts (advertising, sales offices, etc), the centralised reservation system, accounting and management information systems provided by the head office, centralised purchasing, training and educational programmes, etc. An owner should be entitled to know which charges can be billed to his hotel, where to find the contractual basis for such charges and according to what mechanism these costs are allocated among the different properties in the chain. Furthermore, the owner needs to be in a position to ask the operator for a proper accounting of all charges made to the hotel. Unfortunately, management agreements are often not very clear in that respect. As group charges may be quite significant, this lack of transparency often leads to disputes over the legitimacy of such charges during the term of the agreement. ${ }^{4}$ Therefore, a 


\section{Budget control}

\section{Budget}

The right to approve the annual budget is the most important tool of an owner to exercise a certain degree of control over the total cost of operation and the future development of a hotel, provided that the authority of the operator to act on behalf of the owner is contractually limited to the approved budget. Operators should be required to present at least the following to the owner for approval prior to every fiscal year: a detailed operating budget and forecast of operations, including a marketing plan, estimates of gross revenue, operating expenses and GOP, and a detailed capital expenditures budget. The agreement should provide for a specific right of the owner to make objections with respect to every line item within a certain period after the proposed budget has been presented to the owner. If the parties fail to reach agreement on a disputed line item, the amount provided for that line item in the approved budget for the previous fiscal year, adjusted by an index, should apply until an agreement is reached or the dispute is settled. It often makes sense to provide for a special dispute resolution mechanism with respect to unresolved budget items by means of expert arbitration by a sole arbitrator who is a hotel industry expert. Thereby it can be ensured that budget disputes may be resolved quickly and at a reasonable cost rather than having to go through the more complicated, time-consuming and expensive procedure of a full-scale arbitration. Once the budget is approved, it should be made the guideline for all actions taken by the operator in the performance of its rights and obligations under the management agreement, and all expenses the operator may incur on the account of the owner should be limited explicitly to such an approved budget.

\section{Influence over certain major decisions}

In addition to the approval right in connection with the annual budget, owners want to make sure that they have a say with respect to certain other major decisions that may significantly affect the relationship between owner and operator, the long-term operation of the hotel or the value of the property.

\section{General manager}

The general manager is crucial for the success or the failure of any hotel. In addition, he is the main point of contact for the owner in its relationship with the operator. Therefore, it is important for 


\section{Suppliers}

Freedom to sell every owner to make sure that the general manager designated to operate the particular hotel has the necessary professional experience and skills, as well as the right personality to interact with the representatives of the owner on an ongoing basis. Consequently, owners often demand an approval right regarding the appointment of the general manager and the right to ask for his removal based on reasonable grounds. In most cases, the grant of such rights to the owner is legitimate, as long as the parties can agree on a selection procedure that does not allow the owner effectively to prevent the operator from managing the property by continuing to refuse the approval of the candidates presented by the operator.

\section{Approval of certain contracts}

With the budget approval right, the owner already has a certain influence over what kind of liabilities the operator may incur in the course of the operation of the hotel. But this may not be sufficient because the limitations of the approved budget do not restrict the operator with respect to non-cancellable long-term commitments on behalf of the owner that may survive the term of the management agreement, and they give the owner no influence over the selection of certain major suppliers of the hotel. For that reason operators should be required to ask the approval of the owner prior to entering into certain contractually defined long-term contracts as well as certain other major expenditures, regardless of whether the cost of these has already been approved in the budget. In particular, if the owner or its affiliates participate in other businesses, they will insist on such approval rights in order to be able to influence the choice of suppliers. If, on the other hand, the operator is contractually entitled to make certain purchases through its central procurement unit without the owner's approval in every single case, the parties should clearly state how any volume or other discounts resulting from such central purchases are to be allocated between the parties. ${ }^{6}$

\section{Major changes in concept}

Beyond its right to control expenses through the approved budget, an owner is concerned about any major changes in the concept of the hotel if such changes are likely to affect the value of the property or the operating costs in the long term. As a result, many owners want to include a specific right to approve certain major conceptual changes, in particular if they involve higher costs over time.

\section{Sale of hotel asset}

Many older management agreements contractually prevented owners from selling the hotel real estate during the term of the management agreement. But in order to be in a position to profit best from the cycles in the real estate market and to realise the 
highest price for their assets, owners have to be free to sell their property at any time during the term of the agreement. Thus, owners should not accept any restrictive covenants limiting their right to dispose of the hotel. It is quite clear that operators in return will ask for certain protections in such an event (see below).

\section{Remedies in the event of underperformance of operators}

\section{Stand-aside of fees}

\section{Owner's priority}

\section{Transfer of risk}

\section{Performance tests}

Owners often find it hard to accept that operators are entitled to continue earning management fees even in the event that a hotel is operating at a loss or the owner is no longer able to service its debt out of the cash flow earned by the hotel. Consequently, owners frequently demand that the incentive fee (and sometimes even all or part of the base fee) is only paid once the hotel has achieved a certain level of profit (often dependent on the interest the owner has to pay). The stand-aside is usually structured as a loan repayable to the operator out of the profits achieved in later periods. If this is the case, the parties should agree on how such outstanding loans are to be treated in the event of a termination or the expiration of the management agreement. Some agreements also provide that the fees the operator is standing aside from are deemed to be waived and forgiven for good.

\section{Guarantees}

An owner is best protected against the underperformance of its property if the operator agrees to guarantee a defined level of profit. Under such a GOP guarantee the operator would have to make up from its own funds the difference between the actual result of the hotel and the guaranteed amount. As a result, the financial risk of operation is - to the largest extent - transferred from the owner to the operator. From an economic point of view, a management agreement with a performance guarantee is therefore much closer to a lease agreement than to a regular management agreement; however, with only a limited upside potential and more operational restrictions on the part of the operator. That explains why operators are extremely reluctant to consider guarantees and will do so only with respect to hotel projects promising an exceptional return.

\section{Right to terminate}

One of the major concerns of every owner is the possibility to terminate the contract and change operators if the hotel is underperforming. This is a very legitimate request which most operators will not deny, provided the performance standards are reasonable and based on operating projections both parties have agreed upon. ${ }^{7}$ A balanced performance clause should contain the following elements: a clear definition of the performance target (eg GOP or GOP adjusted by debt service or a relative comparison 


\section{Reporting}

Fee structure against the results of a competitive set); an initial exclusion period, such as the first one or two years after the opening date, during which the performance test does not apply; a shortfall deviation allowance providing for reasonable variations of actual performance against projected results; the shortfall time frame allowing the operator to recover from a single bad year (eg two out of three consecutive years during which the operator has to meet the performance target); a right of the operator to cure the shortfall by making up the difference from its own funds in order to avoid termination; and a force majeure exception. ${ }^{8}$

\section{Information and control rights}

Finally, in order to be able to enforce the contractual rights owners are looking for, they need access to information about the performance of the hotel operation and certain control rights in order to verify the accuracy of such information. Owners should be entitled to at least the following: monthly financial reports about the operation of the hotel, including profit and loss statement, balance sheet and cash flow statement; the right to meet with the general manager and senior executives of the head office on a regular basis in order to discuss any matters regarding the operation of the hotel; the right to access and inspect the books of the hotel at all reasonable times; and the right to have the books of the hotel audited by an auditor selected by the owner.

\section{KEY ISSUES FOR OPERATORS}

\section{Compensation}

\section{Management fees}

Whereas owners are concerned to minimise the consideration payable to operators, operators are evidently interested to secure the highest compensation possible. The overall compensation of the operator is normally determined by the relative bargaining power of the parties in a particular project. Generally, operators want to ensure that at least their actual costs of managing a property are covered by the base fee. Regarding the incentive fee, they may be prepared to settle for a lower initial fee percentage if the incentive fee increases on a sliding scale in the event of a higher profit of the hotel. Of course, the fee amount an operator can or will accept depends on other contractual arrangements, such as length of term and the degree of risk the operator is required to take on (standaside, guarantees).

\section{Expenses}

To the extent not covered by the base fee, operators are careful to make sure that all out-of-pocket expenses, group charges and other costs incurred by them in connection with the marketing and operation of a hotel are to be reimbursed by the owner. As 


\section{Securing payment}

\section{Liquidated damages}

\section{Equity contributions}

mentioned above, in order to avoid any disputes in that respect, it is advisable to define clearly the costs an operator is entitled to charge to a hotel for such expenses.

\section{Payment terms}

For an operator it is important that the agreed upon compensation that is owed gets actually paid. This can be ensured by granting the operator the authority to remit to itself from the operating account of the hotel any fees and expenses when due. In order to be able to enforce this right, the operator will have to insist that it has exclusive control over the operating account of the hotel. Furthermore, the operator should verify if the fees can be remitted to its home country net of any local tax deductions or other withholdings. Should this not be the case, the fee base would have to be increased accordingly ('grossing-up').

\section{Termination payment}

If the management agreement is terminated by the owner before the end of the contractually agreed duration for any reason other than in accordance with its terms, or in the event the management agreement is terminated as a result of a disposition of the hotel, the operator is prevented from continuing to earn its fees. Therefore, it is important for the operator to receive a compensation in such an event. It makes sense if owner and operator already agree in the contract on the payment that is due to the operator in such an event as liquidated damages. ${ }^{9}$ The formula for calculating the termination payment should take into account the amount of fees earned in the past and the remaining period of the contract as originally agreed.

\section{Minimise financial exposure}

\section{No investment}

Some owners are attempting to negotiate equity or loan contributions by the operator for the financing of a hotel project. Most operators are extremely reluctant to agree to invest in a hotel project, however, as most major hotel companies have made a policy decision to change from being real-estate companies to operating companies in order to concentrate on what they do best and be in a better position to raise and manage funds for international growth. Other than the improved liquidity, the main reason hotel chains prefer to increase the number of operated properties while making little or no equity investment of their own is the fact that the depreciation expenses resulting from ownership of assets can be minimised for the operator, resulting in higher earnings per share and, consequently, a higher share price for the hotel company. Operators will therefore only consider an investment under exceptional circumstances. In addition, these days many owners are expressing less interest in an investment by the 


\section{Performance guarantees}

Indemnity operator, because they have come to realise that this may weaken their position vis-à-vis the operator, in particular with respect to the possibility to terminate the operator. ${ }^{10}$ Furthermore, if the operator is at the same time an equity partner in the ownership entity of the hotel, this may create a conflict of interest for the operator and even lead to a violation of its fiduciary obligations to the owner. ${ }^{11}$ For this reason, the question of operators having to make an investment seems to have become less of an issue lately.

\section{No obligation to fund}

Operators should insist on the inclusion of an explicit clause stating that they have no obligation to advance any of their own funds to or for the account of the owner or the hotel, or to incur any debt or liability in the performance of their obligations under the management agreement. It is in the nature of a management agreement that the owner has to fund the entire operation of the hotel, including any working capital shortfalls.

\section{No guarantees}

For the reasons explained above, operators will try to avoid any performance guarantees. The significantly increased risk involved with such a commitment is in most cases only acceptable if in return the operator receives a higher fee in the event the hotel is successful or if the project is of strategic importance within the chain.

\section{Insurance}

Sufficient insurance protection is essential in order to limit the exposure of both owner and operator. Therefore, operators are commonly firm with respect to the policies and coverage limits a property has to carry at the expense of the owner. The following policies are of particular importance: commercial general liability insurance; umbrella and excess liability insurance; business interruption insurance; and all-risk property insurance covering the building and its contents. Operators should also ensure that they are named as co-insured under all such policies.

\section{Limited liability}

Operators often demand specific language to the effect that neither they nor their affiliates shall, by reason of operation and management of the hotel in accordance with the management agreement, be liable or otherwise responsible for any debts or liabilities arising in the course of the business of the hotel, except for debts or liabilities arising out of any breach of the agreement or gross negligence by the operator. Furthermore, it is a standard requirement of operators that the owner has to indemnify and hold harmless the operator and its affiliates from and against any claims that may be asserted against them in connection with the operation of the hotel - again with the exception of grossly negligent acts or omissions on the part of the operator. 


\section{Compliance with standard}

\section{Trademark license}

\section{Protection of the brand}

\section{Operational control}

In order to live up to its reputation and protect its brand image, the operator needs to have control over the day-to-day operation of the hotel without any interference from the owner. Any covenants increasing the direct influence of the owner over the operation have the potential of preventing the operator from doing a good job in managing the hotel. This may not only affect the brand, but also diminish the operator's chances to earn the success-based incentive fee. This is the reason why operators normally demand the widest authority possible regarding the operation and management of the hotel.

\section{Provision of sufficient funds by the owner}

One of the most important concerns of every operator is to make sure that the hotel can be operated and maintained in accordance with the quality standards of its brand. A hotel that does not meet such quality standards may deter guests from returning to other member hotels within the operator's system, and is likely to cause considerable damage to the reputation and the image of the hotel chain. The operator will only be able to manage the hotel in accordance with its quality standards if the owner agrees to provide sufficient funds, in particular for regular maintenance, replacements and improvements. Most agreements ${ }^{12}$ provide for a regular contribution into a fund or reserve for FF\&E (furniture, fixtures and equipment). Such contributions range between 1 per cent and 4 per cent of gross revenue, often increasing over time. Since the proper maintenance of a hotel is also in the best interest of the operator, it seems fair that such contributions are treated as operating expenses, ie reducing the basis for calculating the incentive fee.

\section{Control over use of trade marks}

Similar to any other licensor granting the right to use its trade mark, the hotel chain must put certain restrictive covenants on the owner regarding the terms and conditions of the use of the trade mark. Such restrictions should include at least the following: no right of the owner to grant any sublicence; no right of the owner to use the trade mark for other purposes than in connection with the marketing and operation of the hotel by the operator; no right of the owner to attack or register the trade mark or a similar mark in its own name; and no right of the owner to use the trade mark in its corporate name.

\section{Term and termination}

The average initial term of a hotel management agreement in Europe is 19 years, in 55 per cent of all cases with an option to renew. ${ }^{13}$ Shorter-term agreements not only limit the opportunity of 


\section{Effect of termination}

an operator to generate fees, but also negatively affect the brand perception of the public if the operator of a hotel is replaced within a relatively short period after having taken over the property. It follows that operators have at least two reasons for insisting on long agreement terms and to protect themselves against an early termination (eg by providing for a termination payment, as discussed above). On the other hand, owners need to be less concerned about the duration of a contract, provided that the operator agrees to include a performance clause. In addition, the operator will have to ensure that the owner can no longer make use of the trade mark of the operator after the termination or expiration of the agreement (with the exception, for example, of guest items and consumables bearing the mark of the operator that may be used up by the owner during a certain period after the termination) and that all intellectual property developed by the operator is returned to the operator.

\section{'Ownership' of guests}

Many operators consider the customer relationship and the guest database to be some of their most valuable assets. Recently, some owners have started to realise this fact and come to the conclusion that they 'own' the guests of their hotels or should at least benefit from any financial returns guest data can produce. ${ }^{14}$ The unrestricted use of guest information (within the framework of applicable data protection laws) is key to the success of any hotel chain. Only if hotel companies are permitted to use guest data collected at one member hotel for the purposes of marketing other hotels within their system are they able to fulfil their obligations under their existing contracts. Thus, operators should make sure that they are explicitly granted the right to compile and use customer data collected at the hotel - even beyond the term of the management agreement. Once such data are compiled in the central database of the operator and merged with information gathered at other hotels, they should become the property of the operator. On the other hand, the guest data collected at a specific hotel should remain the property of the respective owner, which should also be entitled to use such data on its own (but not the data collected at the other member hotels). Finally, it is recommended that the agreement also provides whether the owner is entitled to receive compensation if the operator sells any of the guest data collected at the owner's hotel to a third party.

\section{CONCLUSION}

These are just the most important issues the parties have to deal with, from both a legal and a business perspective. Of course, there are many additional points that should be covered in an individual hotel management agreement that could not be discussed in this paper. As mentioned initially, both parties must be aware that only a balanced agreement will serve them well over time. Each party 
being willing to try to understand and accommodate the concerns of the other is a very good starting point for a successful long-term business relationship.

\section{References}

1. See also the definition in Eyster, J. (1988) The Negotiation and Administration of Hotel and Restaurant Management Contracts, Cornell University School of Hotel Administration, Ithaca, NY, p. 4.

2. Eyster, J. (1997) 'Hotel management contracts in the US: The revolution continues', Cornell Hotel and Restaurant Administration Quarterly, June, pp. 14-20.

3. Jones Lang LaSalle Hotels (2001) 'Management agreement trends worldwide', Brain Buzz, 15 November.

4. See eg the lawsuit filed by Strategic Hotel Capital against Marriott International Inc. on 20 August, 2002 (text of complaint available at www.hotel-online.com/News/ PR2002_3rd/Aug02_SHCComplaint.html).

5. Eyster, ref. 1 above, p. 57.

6. This is another issue raised in the lawsuit by Strategic Hotel Capital against Marriott International Inc., ref. 4 above.

7. For a more detailed discussion of performance tests see Berger, J. (1997) 'Applying performance tests in hotel management agreements', Cornell Hotel and Restaurant Administration Quarterly, April, pp. 25-31.

8. Based on the components identified by Eyster, J. (1997) 'Hotel management contracts in the US: Twelve areas of concern', Cornell Hotel and Restaurant Administration Quarterly, June, pp. 21-33.

9. Eyster, ref. 1 above, p. 60 et seq.

10. An investment by the operator may create an irrevocable agency with an interest. See Eyster, ref. 2 above, and the court cases discussed therein.

11. Norman, J. (1999) 'Strange bedfellows - Hotel owners and managers as partners', Property Writes (published by Holland \& Knight LLP), Vol. 3, No. 4, pp. 1-4.

12. According to Jones Lang LaSalle Hotels, ref. 3 above, 72.4 per cent of all agreements in Europe.

13. Jones Lang LaSalle Hotels, ref. 3 above.

14. As an example see the lawsuit by Strategic Hotel Capital, ref. 4 above. 